\title{
Strong and sustained activation of the anticipatory unfolded protein response induces necrotic cell death
}

\author{
Mara Livezey $\mathbb{C}^{1} \cdot$ Rui Huang ${ }^{1} \cdot$ Paul J. Hergenrother ${ }^{1,2} \cdot$ David J. Shapiro $^{1}$
}

Received: 28 March 2018 / Revised: 18 May 2018 / Accepted: 24 May 2018 / Published online: 13 June 2018

(c) ADMC Associazione Differenziamento e Morte Cellulare 2018

\begin{abstract}
The endoplasmic reticulum stress sensor, the unfolded protein response (UPR), regulates intracellular protein homeostasis. While transient activation of the reactive UPR by unfolded protein is protective, prolonged and sustained activation of the reactive UPR triggers CHOP-mediated apoptosis. In the recently characterized, evolutionarily conserved anticipatory UPR, mitogenic hormones and other effectors pre-activate the UPR; how strong and sustained activation of the anticipatory UPR induces cell death was unknown. To characterize this cell death pathway, we used BHPI, a small molecule that activates the anticipatory UPR through estrogen receptor $\alpha(E R \alpha)$ and induces death of $E R \alpha^{+}$cancer cells. We show that sustained activation of the anticipatory UPR by BHPI kills cells by inducing depletion of intracellular ATP, resulting in classical necrosis phenotypes, including plasma membrane disruption and leakage of intracellular contents. Unlike reactive UPR activation, BHPI-induced hyperactivation of the anticipatory UPR does not induce apoptosis or sustained autophagy. BHPI does not induce CHOP protein or PARP cleavage, and two pan-caspase inhibitors, or Bcl2 overexpression, have no effect on BHPI-induced cell death. Moreover, BHPI does not increase expression of autophagy markers, or work through recently identified programmed-necrosis pathways, such as necroptosis. Opening of endoplasmic reticulum $\mathrm{IP}_{3} \mathrm{R}$ calcium channels stimulates cell swelling, cPLA2 activation, and arachidonic acid release. Notably, cPLA2 activation requires ATP depletion. Importantly, blocking rapid cell swelling or production of arachidonic acid does not prevent necrotic cell death. Rapid cell death is upstream of PERK activation and protein synthesis inhibition, and results from strong and sustained activation of early steps in the anticipatory UPR. Supporting a central role for ATP depletion, reversing ATP depletion blocks rapid cell death, and the onset of necrotic cell death is correlated with ATP depletion. Necrotic cell death initiated by strong and sustained activation of the anticipatory UPR is a newly discovered role of the UPR.
\end{abstract}

\section{Introduction}

The unfolded protein response (UPR) is an endoplasmic reticulum (EnR) stress-response pathway that maintains protein folding homeostasis and quality control. Three UPR

Edited by D. Vaux

Electronic supplementary material The online version of this article (https://doi.org/10.1038/s41418-018-0143-2) contains supplementary material, which is available to authorized users.

David J. Shapiro

djshapir@life.illinois.edu

1 Department of Biochemistry, University of Illinois, Urbana, IL 61801, USA

2 Department of Chemistry, University of Illinois, Urbana, IL 61801, USA arms, PERK, IRE1 $\alpha$, and ATF6 $\alpha$, act together to decrease the flux of new protein into the EnR, while upregulating molecular chaperones that help fold protein $[1,2]$. Due to its protective effects when weakly activated, the UPR is implicated in the development of numerous cancers [3-6]. In this reactive mode of UPR activation, accumulation of unfolded or misfolded protein triggers UPR activation. A different pathway of UPR activation, originally identified in immune cells and recently shown to be activated by the mitogenic hormones, estrogen, EGF, and VEGF, pre-activates the UPR, anticipating future requirements for increased protein folding capacity [7-9]. Demonstrating clinical relevance, data from $~ 1000$ estrogen receptor $\alpha$ positive $\left(E R \alpha^{+}\right)$breast cancers show that activating a UPR gene signature is a powerful prognostic marker, tightly correlated with subsequent resistance to tamoxifen, reduced time to recurrence, and reduced survival [7]. 
Strong and sustained activation of the reactive UPR induces caspase-dependent apoptosis. Activation of PERK inhibits translation of most mRNAs, increasing translation of ATF4 (activating transcription factor 4). ATF4 induces the transcription factor $\mathrm{CHOP}$ (C/EBP homologous protein) and subsequently GADD34 (growth arrest and DNAdamage-inducible protein 34) [1, 10-13]. When these factors reach a critical threshold and the UPR-activating stress cannot be resolved, apoptosis is triggered [1, 10-13].

The consequences of strong and sustained activation of the anticipatory UPR were largely unknown. We described a small molecule, BHPI, that is a potent preclinical anticancer drug [6, 14-16]. Unlike inhibitors targeting the reactive UPR, BHPI works by inducing hyperactivation of the anticipatory UPR $[12,14,17-19]$. BHPI acts through $\mathrm{ER} \alpha$ to induce rapid activation of phospholipase $\mathrm{C} \gamma$ (PLC $\gamma$ ), which cleaves PIP $_{2}$ to diacylglycerol (DAG) and inositol triphosphate $\left(\mathrm{IP}_{3}\right) . \mathrm{IP}_{3}$ then binds to and opens $\mathrm{IP}_{3}$ receptors $\left(\mathrm{IP}_{3} \mathrm{Rs}\right)$ in the EnR membrane, allowing efflux of calcium stored in the lumen of the EnR into the cell body. This robust and sustained calcium efflux leads to strong and sustained activation of all three arms of the UPR [14]. Through this pathway, BHPI blocks proliferation of, and often kills, $\mathrm{ER} \alpha^{+}$breast, endometrial, and ovarian cancer cells [14-16].

Here we describe how sustained activation of the anticipatory UPR by BHPI kills cancer cells. In contrast to classical UPR activators that kill cells through caspasedependent apoptosis [10-12], BHPI hyperactivates the anticipatory UPR; this causes ATP depletion leading to cell death by a necrosis-like mechanism. Notably, in parallel with necrosis, hyperactivation of the anticipatory UPR activates production of arachidonic acid and causes cell swelling.

\section{Results}

\section{BHPI kills $\mathrm{ERa}^{+}$breast and endometrial cancer cells}

BHPI targets $\mathrm{ER} \alpha^{+}$cancer cells by inducing activation of the anticipatory UPR $[14,15]$. In cell culture, conventional endocrine therapies for breast cancer, tamoxifen and fulvestrant/ICI 182,780 (ICI), inhibit estrogen-ER $\alpha$-dependent proliferation and usually do not kill cancer cells. To explore whether BHPI induces cell death, we performed proliferation assays using tamoxifen-resistant TamR cells [20], T47D cells, and cell lines expressing ER $\alpha$ mutations common in metastatic breast cancer: T47D-ER $\alpha$ Y537S (TYS) and T47D-ER $\alpha$ D538G (TDG) [16]. BHPI not only blocked growth, but also reduced cell number below that initially plated, indicating cell death (Fig. 1a, b). To better quantify cell death, we used an automated assay for cell viability, trypan blue exclusion. Consistent with action through ER $\alpha$, BHPI caused cell death in as little as $24 \mathrm{~h}$ in $\mathrm{ER}^{+}$cell lines, but not in $\mathrm{ER} \alpha^{-}$cell lines (Fig. 1c-e).

\section{Unlike classical UPR activators, BHPI does not induce caspase-dependent apoptosis}

Consistent with activation of caspase-dependent apoptosis, the pan-caspase inhibitor Q-VD-OPH blocks cell death induced by reactive UPR activators, thapsigargin (THG) and bortezomib (BORT) (Fig. 2a) [10-12, 21]. In contrast, BHPI-induced cell death through hyperactivation of the anticipatory UPR is not blocked by the pan-caspase inhibitors Q-VD-OPH or Z-VAD-FMK at 1 (TYS) or $24 \mathrm{~h}$ (T47D and TDG) (Fig. 2b and Supplementary Figure 1a), or by transient overexpression of Bcl2 in TYS cells (Fig. 2c). Furthermore, Z-VAD-FMK had no effect on BHPI's ability to block growth of T47D, TYS, or TDG cells over 4 days (Supplementary Figure 1b). Consistent with earlier reports of impaired caspase-dependent apoptosis in MCF-7 and T47D cells [22-24], we saw only minor PARP (poly-ADPribose polymerase) cleavage upon treatment of T47D, BT474 , or ECC-1 cells with the apoptosis-inducer and general protein kinase inhibitor staurosporine (STS), as well as no visible PARP cleavage with BHPI up to $48 \mathrm{~h}$ (Fig. 2d). Characteristic of apoptotic cell death, STS-treatment of TYS cells caused a distinct increase in Annexin V-FITC staining, followed by propidium iodide (PI) uptake into cells, as determined by flow cytometry. In contrast, BHPItreated cells exhibited a markedly different staining pattern (Supplementary Figure 1c, d).

Reactive UPR activators upregulate the mediator of the UPR-induced apoptotic cascade, CHOP [25-27]. We show BHPI upregulates CHOP mRNA, but due to rapid, sustained, near-quantitative inhibition of protein synthesis through PERK activation [14], CHOP protein is never made (Fig. 2e).

\section{BHPI does not upregulate autophagy}

The contribution of autophagy to cancer is complex. Mild induction of autophagy is protective, while extended activation is toxic [28-30]. Using the inhibitor of lysosomal acidification, chloroquine (CQ), we blocked turnover of proteins in the autophagosome and monitored the production of the autophagy marker LC3-II [28, 29]. Surprisingly, BHPI downregulated LC3-II in T47D, TYS, TDG, and ECC-1 cells (Fig. 3a). A second autophagy marker, Beclin-1 [28, 31], was unchanged or downregulated in T47D, TYS, and TDG cells (Fig. 3b). Lastly, we probed the central regulator of cell metabolism, mTOR (mammalian target of rapamycin). Nutritional deficiency inhibits mTOR and activates autophagy [28, 32, 33]. To monitor mTOR 

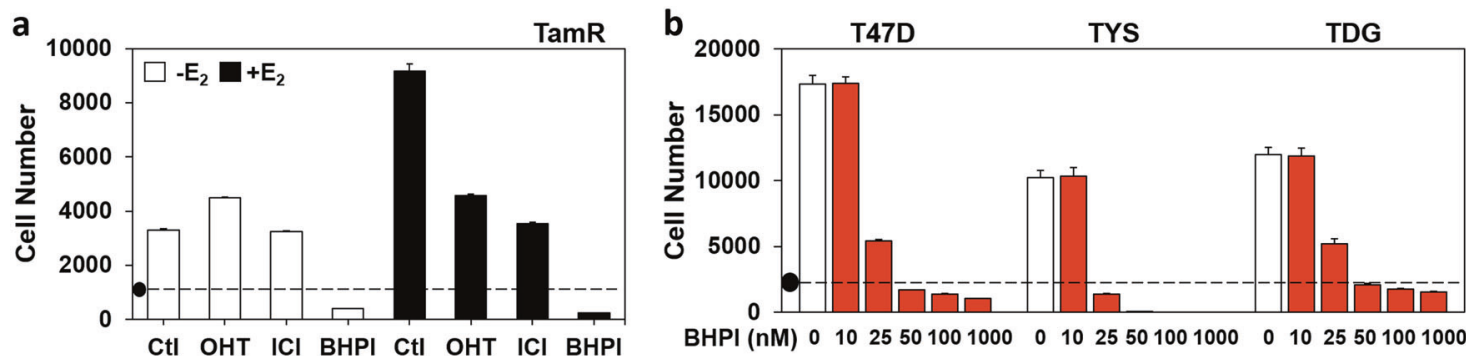

BHPI (nM) $01025501001000 \quad 01025501001000 \quad 01025501001000$
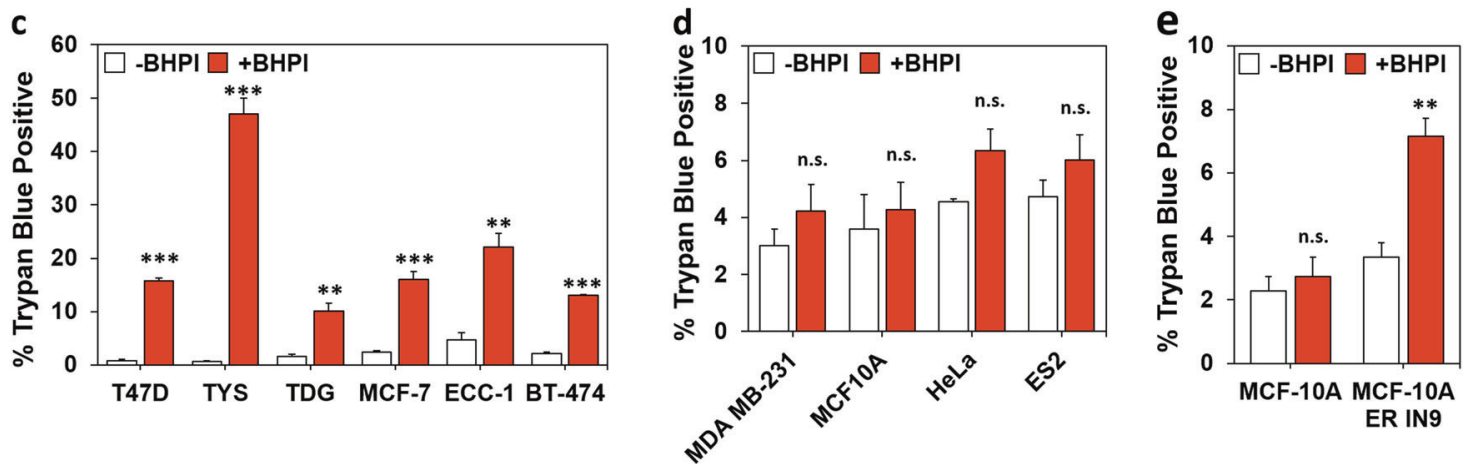

Fig. 1 BHPI kills ER $\alpha+$ breast and endometrial cancer cells. a TamR cell proliferation after 4 days in $8 \%$ charcoal:dextran-treated calf $(\mathrm{CD}$ calf) serum with the indicated treatments: $E_{2} 100 \mathrm{pM}$; $\mathrm{z}$-4-hydroxytamoxifen (OHT, the active form of tamoxifen) $1 \mu \mathrm{M}$; ICI/ fulvestrant $1 \mu \mathrm{M}$; BHPI $100 \mathrm{nM}$. $(\bullet)$ Indicates starting cell number (day 0). b Dose-response study of the effect of increasing concentrations of BHPI on proliferation of T47D, TYS, and TDG cells after 4 days. a, b Alamar Blue assays $(n=8$ biological replicate experiments). c Automated trypan blue exclusion assays of ER $\alpha$ positive cells after $24 \mathrm{~h}$ treatment with $1 \mu \mathrm{M}$ BHPI. d Trypan blue exclusion assays of ER $\alpha$-negative cells after $24 \mathrm{~h}$ treatment with $1 \mu \mathrm{M}$ BHPI. e Trypan blue exclusion assays of isogenic MCF10A and MCF10A $A_{\text {ER IN9 }}$ cells after 24-h treatment with $1 \mu \mathrm{M}$ BHPI. c-e Data is mean \pm s.e.m. $(n=3$ biological replicate experiments). For $(\mathbf{c}-\mathbf{e})$ ${ }^{* *} p<0.01,{ }^{* * *} p<0.001, \mathrm{n} . \mathrm{s}$. $=$ not significant by Student's $t$ test
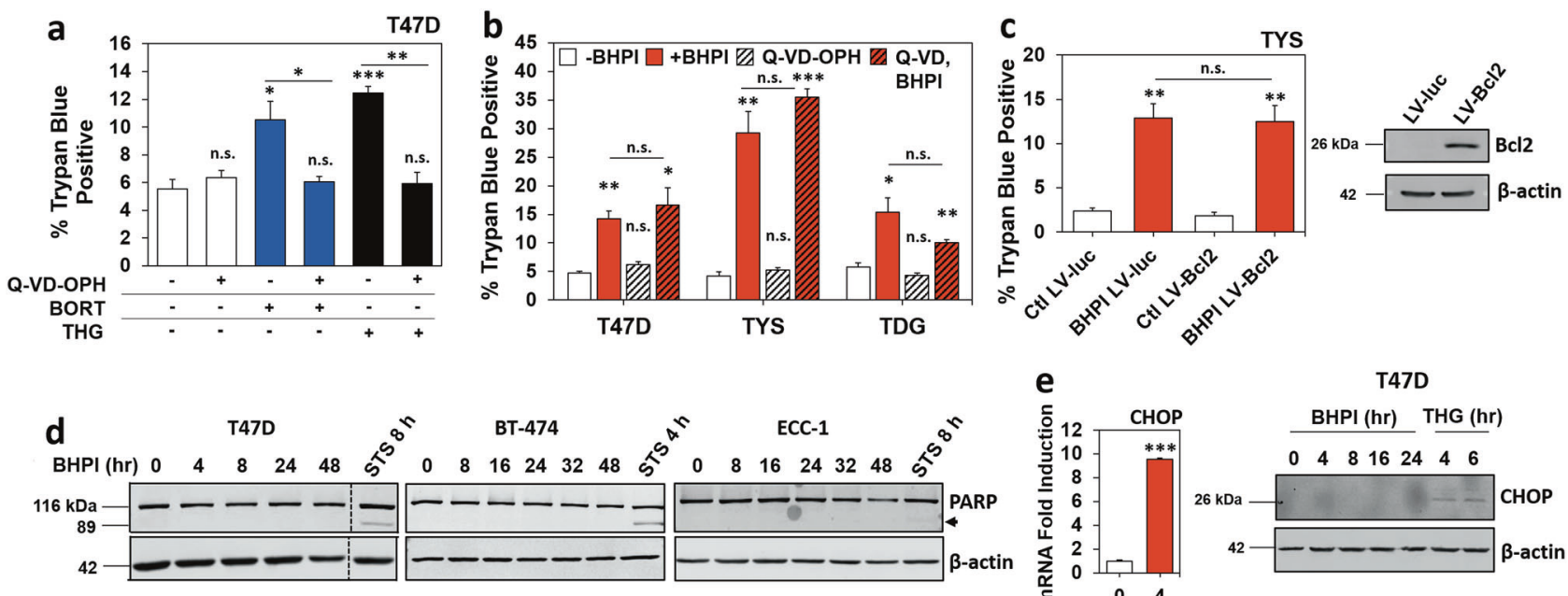

Fig. 2 BHPI does not induce caspase-dependent apoptosis. a Trypan blue exclusion assay of T47D cells after $24 \mathrm{~h}$ treatment with or without $20 \mu \mathrm{M}$ Q-VD-OPH, $100 \mathrm{nM}$ bortezomib (BORT), or $10 \mu \mathrm{M}$ thapsigargin (THG). b Trypan blue exclusion assay of T47D and TDG cells after $24 \mathrm{~h}$, and TYS cells after $1 \mathrm{~h}$ treatment with: $1 \mu \mathrm{M}$ BHPI with or without $20 \mu \mathrm{M}$ Q-VD-OPH. c Trypan blue exclusion assay and western blot analysis of TYS cells infected with lentivirus expressing luciferase (LV-luc) or Bcl2 (LV-Bcl2) after $1 \mathrm{~h}$ treatment with $1 \mu \mathrm{M}$

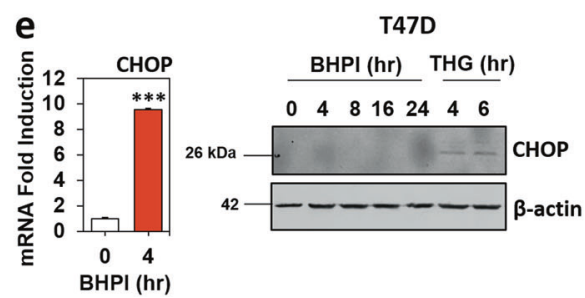

BHPI. a $-\mathbf{c}$ Data are mean \pm s.e.m. $(n=3$ biological replicate experiments), $* p<0.05, * * p<0.01, * * * p<0.001$, n.s. $=$ not significant by Student's $t$ test. d Western blot analysis of cleaved PARP (arrow) in T47D and BT-474 breast cancer cells, and ECC-1 endometrial cancer cells after treatment with $1 \mu \mathrm{M}$ BHPI or $5 \mu \mathrm{M}$ staurosporine (STS) for the indicated times. e mRNA and western blot analysis of CHOP induction in T47D cells treated with $1 \mu \mathrm{M}$ BHPI or $300 \mathrm{nM}$ thapsigargin (THG) for the indicated times 


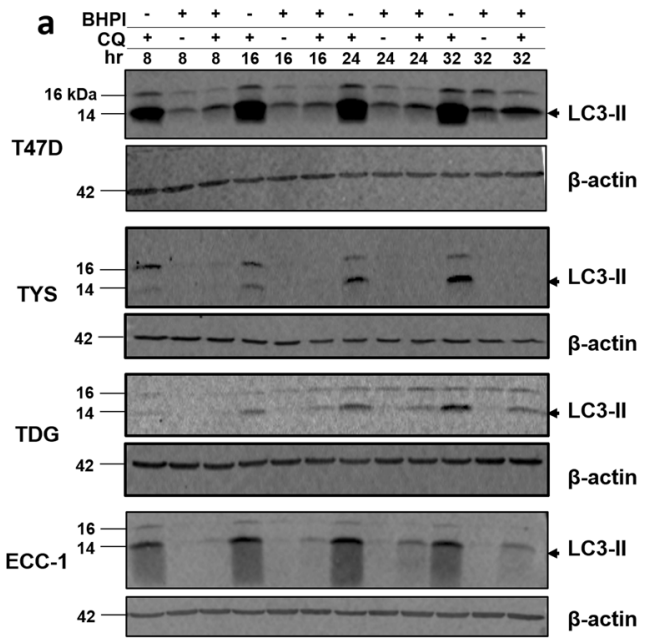

Fig. 3 Autophagy is not upregulated by BHPI. a Western blot analysis of LC3-II production (arrow) in T47D, TYS, TDG, and ECC-1 cells after treatment with $1 \mu \mathrm{M}$ BHPI, $30 \mu \mathrm{M}$ Chloroquine (CQ), or BHPI + CQ for the indicated times. b Western blot analysis of Beclin-1 levels

activation, we looked at a downstream readout of active mTOR, phosphorylated p70S6K. Similar to 24-h serum starvation, BHPI caused a transient decrease in p70S6K phosphorylation at $8 \mathrm{~h}$, but $\mathrm{p} 70 \mathrm{~S} 6 \mathrm{~K}$ phosphorylation recovered and was stable from 16 to $48 \mathrm{~h}$ (Fig. 3c). This indicates extended BHPI treatment leads to mTOR activation and inhibition of autophagy.

\section{BHPI induces rapid swelling of cancer cells}

While there was no evidence for BHPI-induced programmed cell death, we noticed that hours after BHPI treatment, cells appeared swollen. Swelling is associated with diverse lethal pathologies, including edema, hypertrophy, and necrosis [34]. BHPI, but not the inactive structurally related compound 8, caused concentration-dependent cell swelling (Supplementary Figure 2a) [14]. Cell swelling is ER $\alpha$-dependent; $E R \alpha^{+}$cell lines exhibited significant swelling within $1 \mathrm{~h}$, while $\mathrm{ER} \alpha^{-}$ cell lines did not (Fig. 4a, b). Moreover, siRNA knockdown of ER $\alpha$ (ESR1) significantly attenuated swelling. Since knockdown was incomplete and BHPI is an extremely potent activator of the anticipatory UPR, some residual swelling was observed (Supplementary Figure 2b). Interestingly, rapid swelling was closely followed by an increase in death in TYS and MCF-7 cells (Fig. 4c).

The mitogenic hormones estrogen $\left(\mathrm{E}_{2}\right)$, EGF, and progesterone $\left(\mathrm{P}_{4}\right)$ weakly activate the anticipatory UPR $[7,8,16]$. Demonstrating the unique ability of BHPI to cause cell swelling, weak activation of the anticipatory UPR by $\mathrm{E}_{2}, \mathrm{EGF}$, and $\mathrm{P}_{4}$ did not induce swelling (Supplementary Figure 2c). Additionally, reactive UPR activators bortezomib (BORT) and tunicamycin (TUN) did not cause swelling (Supplementary Figure 2d). Although the reactive UPR activator THG and

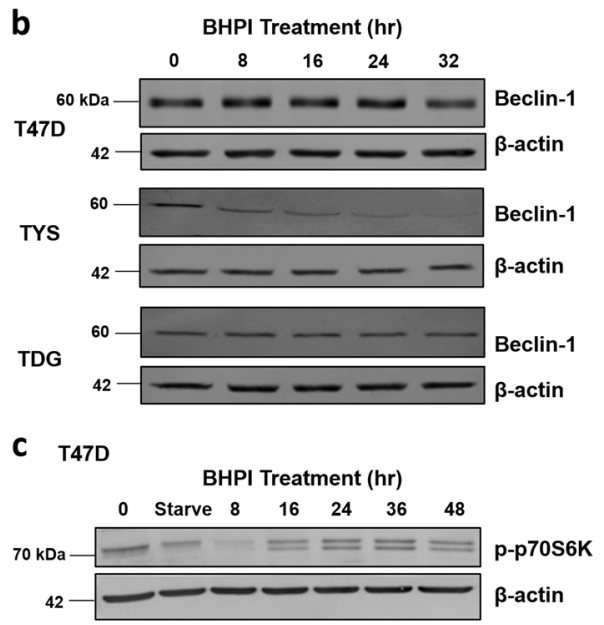

in T47D, TYS, and TDG cells after treatment with $1 \mu \mathrm{M}$ BHPI for the indicated times. $\mathbf{c}$ Western blot analysis of phosphorylation of p70S6K in T47D cells after treatment with $1 \mu \mathrm{M}$ BHPI for the indicated times, or after serum starvation (Starve) for $24 \mathrm{~h}$

BHPI produce similar increases in cytosolic calcium [14], THG did not cause swelling (Supplementary Figure 2e). Moreover, the endocrine therapies z-4-hydroxytamoxifen (OHT) and ICI/ fulvestrant or the chemotherapeutic doxorubicin (DOX) did not cause cell swelling, and paclitaxel (PAC) caused minimal swelling (Supplementary Figure 2d).

Since BHPI was unique in its ability to cause rapid swelling, we asked whether this was specific to hyperactivation of the anticipatory UPR. We showed that 2-APB completely blocks calcium release from EnR $\mathrm{IP}_{3} \mathrm{R}$ channels following BHPI treatment and after weak activation of the anticipatory UPR [7, 14, 15]. 2-APB blocked BHPI-induced swelling (Fig. 4d). Supporting BHPI acting through anticipatory UPR hyperactivation, BHPI-induced swelling in T47D cells maintained in calcium-free medium (Fig. 4d). Moreover, the calcium chelator, BAPTA-AM, completely blocked swelling (Fig. 4d). We hypothesized that BHPI might be eliciting cell swelling by modulating ion channels. However, inhibitors targeting individual ion channels/pumps did not block swelling (Fig. 4e). Since BHPI was not able to swell cells in salt-free, isosmotic medium, extracellular ions are necessary for BHPI-induced swelling (Fig. 4f). Taken together, this suggests that BHPI hyperactivation of the anticipatory UPR triggers cell swelling, and that nonspecific increases in cytosolic calcium, or activation of the reactive UPR, do not trigger cell swelling.

\section{BHPI activation of CPLA2 leads to arachidonic acid release}

Calcium signaling and membrane stretching activate cytosolic phospholipases A2 (cPLA2s), resulting in cleavage of membrane phospholipids to form arachidonic acid (AA) [35-37]. AA and its metabolites can further alter cell volume 

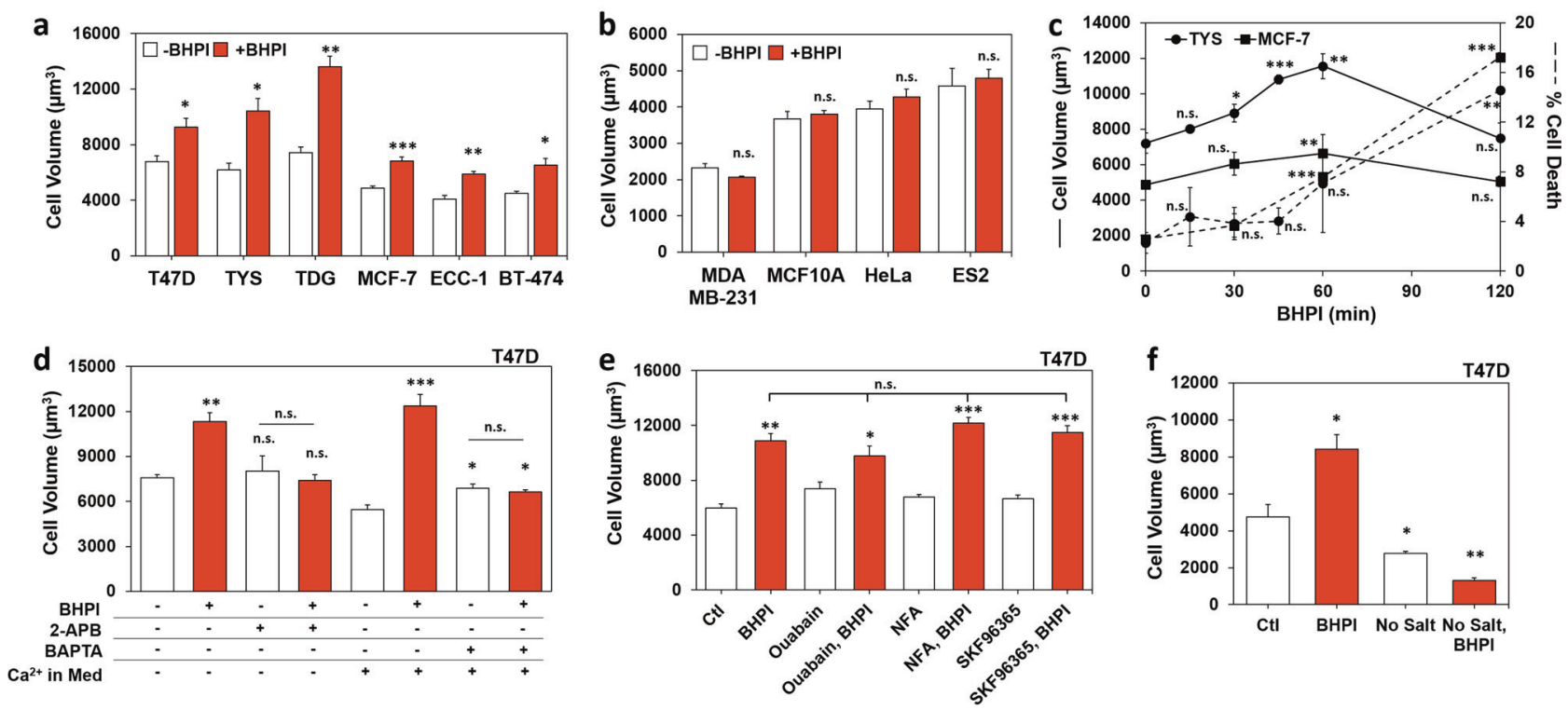

Fig. 4 BHPI-ER $\alpha$-induced cell swelling is linked to early steps in the anticipatory UPR. a Cell volume in ER $\alpha$-positive cells treated with $1 \mu \mathrm{M}$ BHPI for $1 \mathrm{~h}$ (T47D, TYS, TDG, MCF-7, and BT-474), or $30 \mathrm{~min}$ (ECC-1). b Cell volume in ER $\alpha$-negative MDA MB-231, MCF10A, HeLa, and ES2 cells treated with $1 \mu \mathrm{M}$ BHPI for $1 \mathrm{~h}$. c Time course of the effect of BHPI on cell volume and cell death in TYS and MCF-7 cells. Cell volume (solid lines) and cell death (dashed lines) were assayed by trypan blue exclusion in cells treated with $50 \mathrm{nM}$ BHPI (TYS), or $100 \mathrm{nM}$ BHPI (MCF-7). d Blocking the increase in intracellular calcium with 2-APB, or with the calcium chelator, BAPTA-AM (BAPTA), prevents the BHPI-induced increase in cell

by modulating the activity of ion channels [38]. Additionally, AA induces death in glial cells [39]. BHPI elicited time-dependent AA release in T47D cells and AA release correlated with cell swelling (Fig. 5a). Furthermore, within $1 \mathrm{~h}$, BHPI-induced concentration-dependent release of AA from several cell lines (Fig. 5b). Neither control compound 8 (Supplementary Figure 3a) nor THG (Fig. 5c) caused release of AA, but THG was able to block BHPI-induced AA release (Fig. 5c). Importantly, THG did not block swelling in T47D or TYS cells, indicating membrane stretching is not sufficient to activate cPLA2 (Supplementary Figure $3 b$ ). Consistent with cPLA2 as the source of AA, the cPLA2 inhibitor quinacrine (Quin) blocked release of AA from T47D cells (Fig. 5c). Suggesting AA contributes minimally to cell swelling, adding AA to culture medium increased cell size modestly (Supplementary Figure 3c). Additionally, while Quin blocked cell swelling, the block was only partially reversed by adding back AA (Fig. 5d).

Demonstrating that neither AA release nor cell swelling are directly related to rapid cell death, while Quin blocked both AA release and swelling, it did not block death in TYS cells, which die rapidly following BHPI treatment (Fig. 5e). Although AA is the precursor for pro-inflammatory prostaglandins, BHPI treatment for $24 \mathrm{~h}$ only elicited a minimal increase in prostaglandin (Fig. 5f) [40, 41]. volume. Cell volume in T47D cells treated for $1 \mathrm{~h}$ with vehicle, $50 \mathrm{nM}$ BHPI, $100 \mu \mathrm{M}$ 2-APB, or BHPI + 2-APB in calcium-free isosmotic medium, or vehicle, $20 \mu \mathrm{M}$ BAPTA-AM, or BHPI + BAPTA-AM. e, $\mathbf{f}$ Cell volume of T47D cells after $1 \mathrm{~h}$ treatment as indicated. e BHPI $50 \mathrm{nM}$; ouabain $2 \mu \mathrm{M}\left(\mathrm{Na}^{+} / \mathrm{K}^{+}\right.$ATPase inhibitor); niflumic acid (NFA) $100 \mu \mathrm{M}$ (nonspecific anion channel inhibitor); SKF96365 $10 \mu \mathrm{M}$ (TRP channel inhibitor). f BHPI $50 \mathrm{nM}$; isosmotic salt-free sucrose buffer (No Salt). Data are mean \pm s.e.m. $(n=3$ biological replicate experiments) ${ }^{*} p<0.05,{ }^{*} p<0.01, * * * p<0.001$, n.s. $=$ not significant by Student's $t$ test

\section{BHPI induces necrotic cell death}

While neither swelling nor AA production is responsible for rapid cell death, they are associated with inflammatory forms of cell death, such as necrosis. Necrotic cell death has fewer well-defined markers than apoptosis or autophagy; necrosis often involves disruption of calcium homeostasis, cell swelling, ATP depletion and, ultimately, loss of plasma membrane integrity [42-45]. We observed loss of membrane integrity in T47D, TYS, and TDG cells by monitoring leakage of cellular HMGB1 (high mobility group box 1) (Fig. 6a) and LDH (lactate dehydrogenase) into the medium (Supplementary Figure 4a). Necrosis is best assessed by morphological changes visualized by transmission electron microscopy (TEM). TEM images of T47D, TYS, and TDG cells treated with BHPI for 24 or $48 \mathrm{~h}$ revealed morphological changes characteristic of necrosis, including lysosomal and mitochondrial swelling, translucent cytoplasm, and ultimately, plasma membrane disintegration (Fig. 6b and Supplementary Figure 4b) [44-46]. Cells treated with BHPI were similar to cells treated with a necrosis-inducing concentration of $\mathrm{H}_{2} \mathrm{O}_{2}$ for $24 \mathrm{~h}$ (Supplementary Figure 4b) [47].

There is increasing interest in programmed necrosis, or necroptosis. Initiation of necroptosis by diverse stimuli requires receptor-interacting proteins 1 or 3 (RIP1, RIP3) 

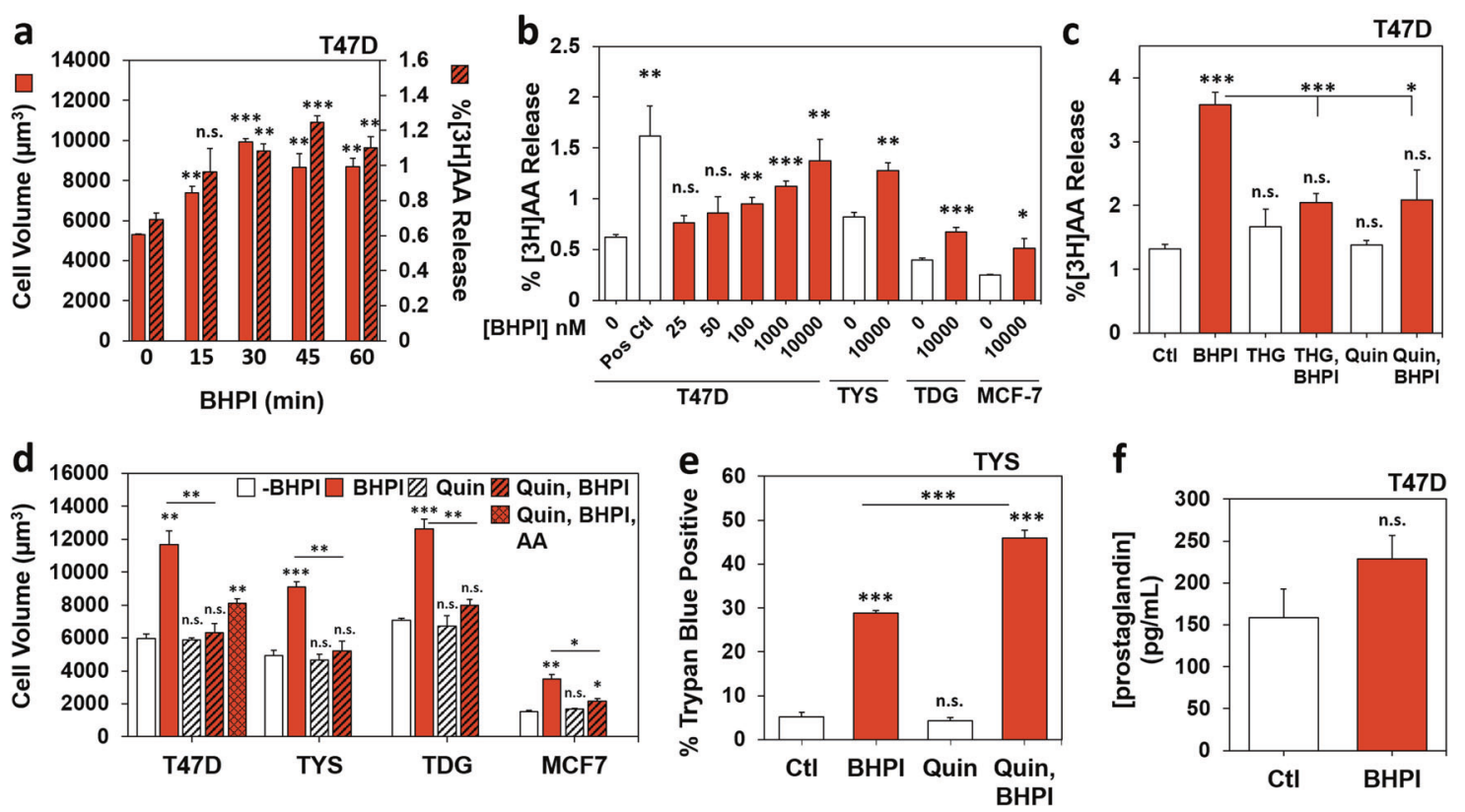

Fig. 5 BHPI activation of cPLA2 causes release of arachidonic acid (AA). a Time course showing a correlation between increased AA release and increased cell volume in BHPI-treated T47D cells. Time course of changes in cell volume (solid bars) and ${ }^{3} \mathrm{H}$-arachidonic acid release $\left(\left[{ }^{3} \mathrm{H}\right] \mathrm{AA}\right.$, hatched bars) after treatment of T47D cells with vehicle or with $10 \mu \mathrm{M}$ BHPI. Data are mean \pm s.e.m. (solid bars, $n=3$ biological replicate experiments; hatched bars, $n=4$ biological replicate experiments). b Concentration-dependent release of $\left[{ }^{3} \mathrm{H}\right] \mathrm{AA}$ from T47D, TYS, TDG, and MCF-7 cell membranes after treatment for 45 min with vehicle or the indicated concentration of BHPI. Positive control (Pos Ctl) is 150 mOsm buffer with $1 \mu \mathrm{M}$ THG. c THG and the cPLA2 inhibitor quinacrine (Quin) block the BHPI-mediated increase in AA. Release of $\left[{ }^{3} \mathrm{H}\right] \mathrm{AA}$ from T47D cell membranes after treatment

[48, 49]. To test the involvement of RIP1 and RIP3, we used the inhibitors 7-Cl-O-Nec-1 (Nec-1) and GSK872, respectively. Nec-1 and GSK872 did not reduce killing by BHPI at 1 (TYS) or $24 \mathrm{~h}$ (T47D and TDG), failed to restore proliferation over 4 days, and instead, increased cell death (Supplementary Figure 4c, d). Independent of necroptosis, these compounds are known to inhibit cell proliferation and induce apoptosis $[49,50]$.

\section{Necrotic death is an early outcome of anticipatory UPR hyperactivation and ATP depletion is critical}

BHPI-induced hyperactivation of the anticipatory UPR results in robust PERK activation and rapid, near-quantitative inhibition of protein synthesis at initiation [14]. The potent activator of eIF2B, ISRIB, reversed BHPI-induced inhibition of protein synthesis (Fig. 7a) [51]. At later times, BHPI also inhibits protein synthesis at elongation, through activation of AMPK and phosphorylation of eEF2; and ISRIB did not reverse inhibition of protein synthesis (Supplementary Figure 5a) [14]. While ISRIB completely blocked BHPI-induced inhibition of protein synthesis, it did not block rapid necrotic death in TYS cells (Fig. 7b). for 45 min with vehicle, $1 \mu \mathrm{M}$ thapsigargin (THG), $1 \mu \mathrm{M}$ BHPI, BHPI + THG, $300 \mu \mathrm{M}$ Quin, or BHPI + Quin. d Effect of Quin and AA on BHPI-induced changes in cell volume. Volume of T47D, TYS, TDG, and MCF-7 cells after treatment for $1 \mathrm{~h}$ with vehicle, $50 \mathrm{nM}$ BHPI, $300 \mu \mathrm{M}$ Quin, $250 \mu \mathrm{M}$ AA, BHPI + Quin, or BHPI + Quin + AA. e Quin does not block BHPI-induced cell death. Trypan blue exclusion assay for cell death in TYS cells treated for $1 \mathrm{~h}$ with vehicle, $1 \mu \mathrm{M}$ BHPI, $300 \mu \mathrm{M}$ Quin, or BHPI + Quin. f ELISA determination of prostaglandin production from T47D cells after treatment for $24 \mathrm{~h}$ with $10 \mu \mathrm{M}$ BHPI. Data are mean \pm s.e.m. b, c, $\mathbf{f}(n=4$ biological replicate experiments), d, e ( $n=3$ biological replicate experiments). For (a-f) $* p<0.05, * * p<0.01, * * * p<0.001$, n.s. $=$ not significant by Student's $t$ test

We next asked if events upstream of PERK activation in the anticipatory UPR trigger necrosis, specifically, calcium release from $\mathrm{IP}_{3}$ Rs. Over several days, knockdown of some essential components of the anticipatory UPR, such as all three $\mathrm{IP}_{3} \mathrm{R}$ calcium channel isoforms, results in substantial damage to cells. Moreover, the powerful $\mathrm{IP}_{3} \mathrm{R}$ signal induced by hyperactivation of the anticipatory UPR could not be blocked by the $\mathrm{IP}_{3}$ sponge, or by $\mathrm{IP}_{3}$ phosphatase $[8$, 52]. Notably, 2-APB completely blocked rapid cell death in TYS and MCF-7 cells (Fig. 7c). Demonstrating PLC $\gamma$ activation and $\mathrm{IP}_{3}$ production are necessary for rapid cell death, siRNA knockdown of PLC $\gamma$ nearly abolished BHPIinduced cell death (Supplementary Figure 5b).

$\mathrm{IP}_{3}$ binds to and opens $\mathrm{IP}_{3}$ receptor $\left(\mathrm{IP}_{3} \mathrm{R}\right)$ calcium channels causing a rapid and sustained release of calcium from the lumen of the EnR into the cytosol [14, 15]. This creates an ATP-depleting futile cycle, where energy-dependent EnR SERCA pumps try to restore calcium homeostasis by pumping the calcium back into the lumen of the EnR, only to have it leak back out due to sustained opening of $\mathrm{IP}_{3} \mathrm{Rs}[14$, 15]. Strikingly, the inhibitor of the SERCA pump, THG, significantly reduced rapid BHPI-induced cell death in TYS and MCF-7 cells (Fig. 7d). We previously showed that in 
a

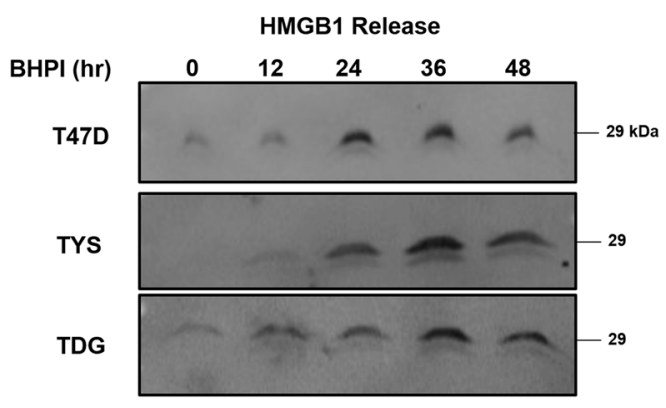

b BHPI (hr)

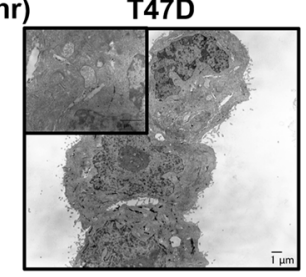

24

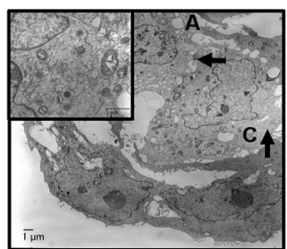

TYS
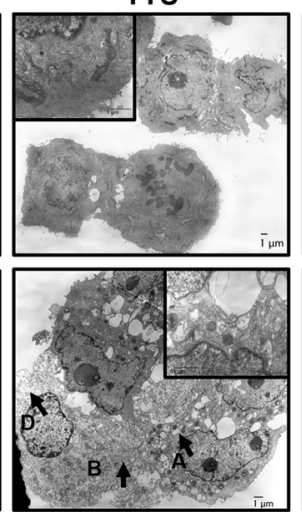

TDG

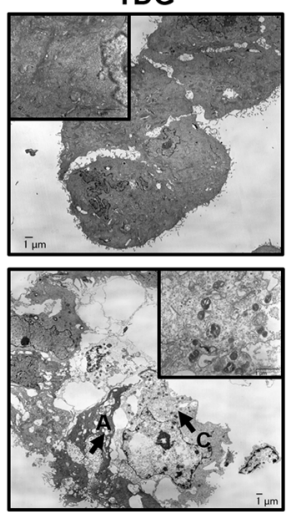

Fig. 6 BHPI-induced cell death exhibits a necrotic phenotype. a Western blot analysis of HMGB1 release into the cell culture supernatant at the indicated time points from T47D, TYS, and TDG cells treated with $1 \mu \mathrm{M}$ BHPI. Equal volumes of culture supernatant were loaded for analysis. b Transmission electron microscopy (TEM)

MCF-7 cells, THG blocks BHPI-induced ATP depletion [14]. Consistent with a critical role for ATP depletion in BHPIinduced necrotic death, BHPI caused significant ATP depletion in TYS cells within $1 \mathrm{~h}$ that was blocked by THG (Fig. 7e). We therefore compared the time course of BHPIinduced ATP depletion with the time course of cell death (note that the apparent increase in cell viability at $24 \mathrm{~h}$ in TYS cells in Fig. 7e is due to $23 \%$ loss of disintegrated dead cells that are not visualized as trypan blue positive, we estimate viability to be 59\%). Supporting a central role for ATP depletion in cell death, the time course of the onset of necrotic cell death in T47D, TYS, and TDG cells is correlated with the onset of ATP depletion (Fig. 7e).

\section{Discussion}

Tumors must proliferate and overcome hypoxia, nutritional deprivation, and stress due to chemotherapy. In response, tumors activate the reactive UPR, which helps them overcome the stress, survive, and metastasize [2]. Activation of key UPR components, including BiP/GRP78/HSPA5 and $\mathrm{XBP} 1$, is implicated in development of diverse cancers including breast, lymphoma, lung, and glioma [3]. Although strong and sustained activation of the reactive UPR triggers caspase-dependent apoptosis, most drugs that target the reactive UPR usually work by inhibiting action of a UPR component and therefore must avoid toxicity in cells with a high secretory load [12, 17-19]. An attractive alternative is targeting the anticipatory UPR that we, and others, showed is activated by the mitogenic hormones estrogen, progesterone, EGF, and VEGF [7-9]. Instead of inhibiting a component of this pathway, BHPI exploits the moderate activation of this protective pathway in $\mathrm{ER}^{+}$cancer cells by hyperactivating the anticipatory UPR [14]. This pushes images of T47D, TYS, and TDG cells treated with $1 \mu \mathrm{M}$ BHPI for 0 or $24 \mathrm{~h}$. Letters with arrows indicate features characteristic of necrotic morphology: a swollen vacuoles, b swollen mitochondria, c cytoplasmic lightening, d membrane rupture/"ghost" cells

UPR activation in $\mathrm{ER}^{+}{ }^{+}$cancer cells into the lethal range. Thus, BHPI is both a promising preclinical anticancer drug with a unique mode of action [14, 15], and a powerful tool for analyzing the death pathway induced by strong and sustained activation of the anticipatory UPR.

A unique feature of strong and sustained activation of the anticipatory UPR is rapid ATP depletion. Well-studied activators of the reactive UPR do not induce ATP depletion. Therefore, the consequences for cancer cell fate of BHPIinduced hyperactivation of the anticipatory UPR, sustained opening of $\mathrm{IP}_{3} \mathrm{R}$ calcium channels, and subsequent ATP depletion were unclear.

We explored the relationships between three events triggered by BHPI treatment: rapid cell swelling, release of arachidonic acid, and cell death. A model depicting our findings is Supplementary Figure 6. The most striking consequence of anticipatory UPR activation, disruption of calcium homeostasis, and ATP depletion is necrotic cell death [45]. Consistent with necrosis, we observed increased membrane permeability shown by leakage of intracellular proteins such as HMGB1 and LDH (Fig. 6a, Supplementary Figure 4a). Furthermore, TEM images of T47D, TYS, and TDG cells treated with BHPI showed classical features of necrotic morphology including lysosomal and mitochondrial swelling and lightening of the cytoplasm (Fig. 6b). At high concentrations, $\mathrm{H}_{2} \mathrm{O}_{2}$ induces disruption of calcium homeostasis, ATP depletion, and necrosis [44, 45, 47, 53]. Consistent with BHPI inducing necrotic cell death, BHPI and $\mathrm{H}_{2} \mathrm{O}_{2}$-treated cells exhibited similar morphology. Notably, after $24 \mathrm{~h}$ in TYS cells or $48 \mathrm{~h}$ in T47D and TDG cells, we observed a "ghost" cell population exhibiting severely disintegrated membranes and massive leakage of intracellular contents (Fig. 6b, Supplementary Figure 4b).

Cytosolic calcium overload, such as is seen with BHPIopening of EnR IP ${ }_{3} \mathrm{R}$ calcium channels, is implicated in both 

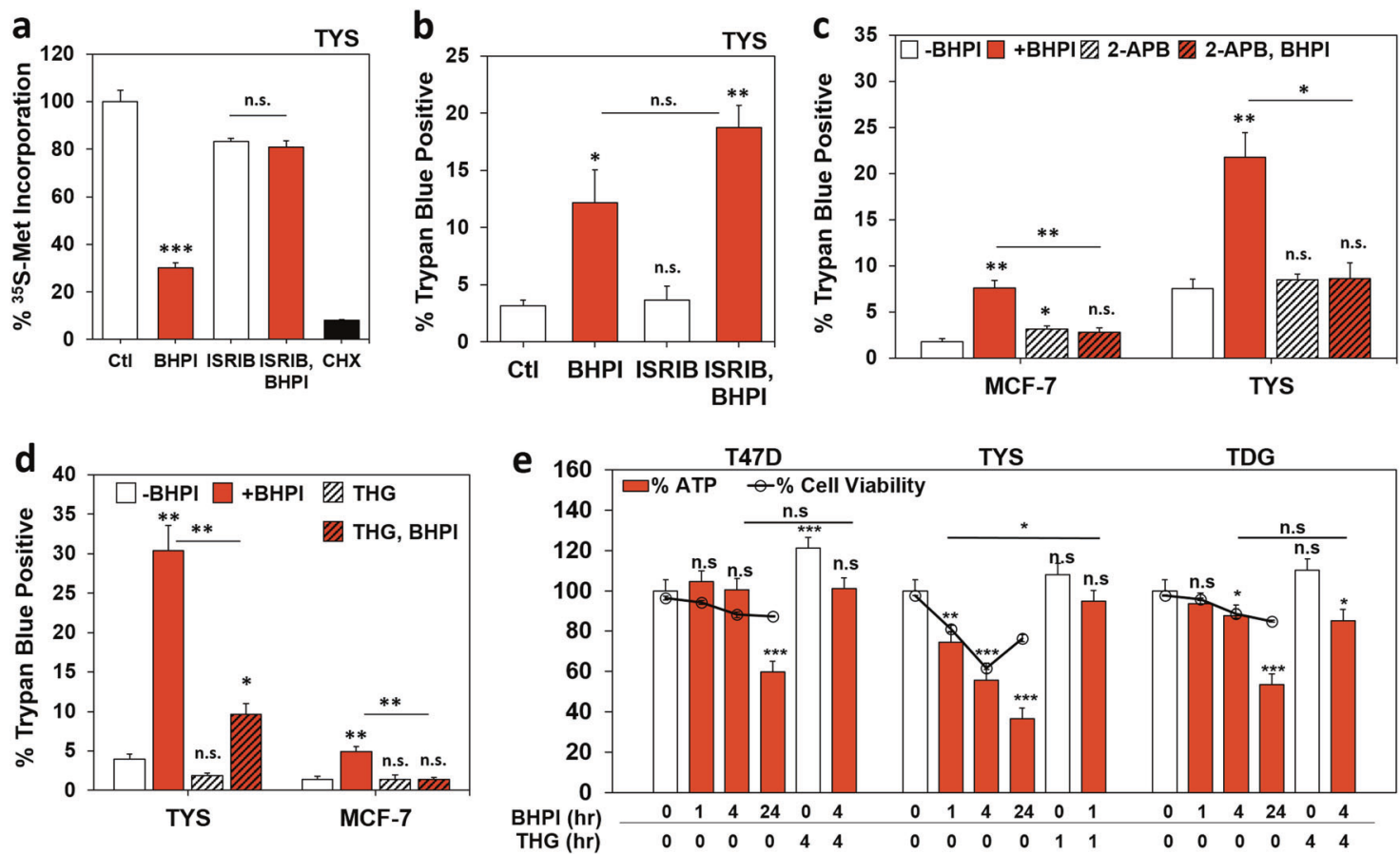

Fig. 7 BHPI-induced necrosis is an upstream effect of anticipatory UPR activation and requires ATP depletion. a Incorporation of ${ }^{35} \mathrm{~S}$-methionine into newly synthesized protein in TYS cells treated for $1 \mathrm{~h}$ with vehicle (set to $100 \%$ ), $50 \mathrm{nM}$ BHPI, $200 \mathrm{nM}$ ISRIB, BHPI + ISRIB, or $10 \mu \mathrm{M}$ cyclohexamide (CHX). b ISRIB does not prevent BHPI-induced cell death. Trypan blue exclusion assay for cell death in TYS cells after $1 \mathrm{~h}$ treatment with vehicle, $1 \mu \mathrm{M}$ BHPI, $200 \mathrm{nM}$ ISRIB, or BHPI + ISRIB. c Locking the EnR $\mathrm{IP}_{3} \mathrm{R}$ calcium channels closed with 2-APB blocks BHPI-induced cell death. Trypan blue exclusion assay for cell death in MCF-7 and TYS cells treated for $1 \mathrm{~h}$ with vehicle, $1 \mu \mathrm{M}$ BHPI, $100 \mu \mathrm{M}$ 2-APB, or BHPI + 2-APB. d THG inhibits BHPI-induced cell death. Trypan blue exclusion assay for cell death in TYS and MCF-7 cells treated for $1 \mathrm{~h}$ with vehicle, $1 \mu \mathrm{M}$ BHPI, $10 \mu \mathrm{M}$ THG, or BHPI + THG. e Time-dependent decline in

apoptosis and necrosis [54]. Demonstrating calcium release from $\mathrm{IP}_{3} \mathrm{Rs}$ is necessary for cell death, 2-APB completely blocked rapid death in TYS and MCF-7 cells (Fig. 7c). Prolonged activation of the reactive UPR results in apoptotic cell death. However, near-quantitative inhibition of protein synthesis by BHPI blocks production of pro-apoptotic UPR mediators, such as CHOP (Fig. 2e). Interestingly, we also observed inhibition of autophagy upon BHPI treatment (Fig. 3). It is possible that the reduced requirement for amino acids due to near-quantitative inhibition of protein synthesis by BHPI is linked to inhibition of autophagy. Inhibiting autophagy may exacerbate BHPI-induced UPR activation and ATP depletion, and consequently, necrotic cell death.

Programmed cell death by apoptosis and autophagy require ATP; activation of caspase-9 in the apoptosome and phagophore elongation are ATP-dependent [55]. When ATP is depleted, cells fail to initiate apoptosis and/or autophagy, and necrotic cell death is induced [54]. Commonly, necrotic ATP depletion is caused by mitochondrial dysfunction after disruption of calcium homeostasis [56]. In
ATP levels in BHPI-treated cells correlates with cell death. Measurement of whole-cell ATP levels (bars) and trypan blue exclusion (overlay, [o]) after treatment for the indicated times with vehicle, $1 \mu \mathrm{M}$ BHPI, $10 \mu \mathrm{M}$ THG, or BHPI + THG. For TYS cells, 23\% of cells have died at early times and disintegrated at $24 \mathrm{~h}$ and are not counted by the instrument. Therefore, the percentage of trypan blue excluding cells declines at $24 \mathrm{~h}$, the total number of dead cells (trypan blue positive + disintegrated cells) is estimated to be $\sim 59 \%$. Data are mean \pm s.e.m. a ( $n=4$ biological replicate experiments), $\mathbf{b}-\mathbf{d}(n=3$ biological replicate experiments), e $(n=5$ biological replicate experiments; ATP) ( $n=3$ biological replicate experiments; cell viability) ${ }^{*} p<0.05, * * p<0.01, * * * p<0.001$, n.s. $=$ not significant by Student's $t$ test

contrast, BHPI indirectly activates SERCA pumps, causing cells to consume ATP faster than they produce it, a mechanism reminiscent of PARP-mediated ATP depletion after excessive DNA damage [44]. We analyzed the role of ATP depletion using THG, which inhibits ATP-dependent SERCA pumps in the EnR and reverses BHPI-mediated ATP depletion [14]. Consistent with loss of ATP playing a pivotal role in activating necrotic cell death, and despite inducing an increase in intracellular calcium similar to that seen with BHPI [14], THG potently reversed rapid death in TYS and MCF-7 cells (Fig. 7d). Since THG is lethal over time [11], we could not test the effect of THG on T47D and TDG cells. Supporting a role for ATP depletion in necrotic cell death following sustained activation of the anticipatory UPR, death and ATP depletion were correlated in T47D, TYS, and TDG cells (Fig. 7e). Notably, in TYS cells, but not in T47D and TDG cells, BHPI induces both a decline in ATP levels and cell viability in $1 \mathrm{~h}$.

Within $1 \mathrm{~h}$ and prior to cell death, BHPI caused ER $\alpha$ mediated, time and concentration-dependent cell swelling 
(Fig. 4a-c, Supplementary Figure 2a, b). Cell swelling is associated with and is commonly a precursor to necrosis [34]. Swelling was specific to BHPI's unique mechanism of action and required $\mathrm{ER} \alpha$, opening of EnR $\mathrm{IP}_{3} \mathrm{R}$ calcium channels, intracellular calcium, and extracellular ions (Fig. 4d, f). Weak anticipatory UPR activators, reactive UPR activators, endocrine therapies, and chemotherapeutic drugs did not cause cell swelling (Supplementary Figure 2c-e). Notably, blocking BHPI-mediated ATP depletion with THG did not inhibit rapid swelling (Supplementary Figure 3c), but did block death (Fig. 7d).

In contrast, ATP depletion was required for cPLA2 activation as THG blocked AA release from membranes (Fig. 5c). While assaying ATP levels in the entire T47D cell at $1 \mathrm{~h}$ did not show ATP depletion, it is possible that local ATP levels at membranes are reduced. Interestingly, while calcium activates cPLA2 [35-37], THG, which increases intracellular calcium but does not reduce ATP levels, did not induce AA release. Instead, THG blocked BHPImediated AA release (Fig. 5c). Additionally, even though both THG and the cPLA2 inhibitor Quin block AA release from cells, only Quin blocked cell swelling (Fig. 5d). Within cells, AA can be converted to proinflammatory prostaglandins by COX (cyclooxygenase) [40, 41]. We saw a modest, not statistically significant, increase in prostaglandins in the medium from BHPI-treated cells. Together, BHPI-mediated release of AA metabolites, and necrotic leakage of immunomodulatory proteins such as HMGB1, might create an inflammatory tumor environment conducive to increased immune detection and killing of tumor cells in vivo [57, 58].

While we found that rapid cell swelling, AA release, and cell death are linked to early steps in sustained activation of the anticipatory UPR and require calcium release from $\mathrm{IP}_{3} \mathrm{Rs}$, they are parallel and distinct results. Notably, ATP depletion independently activates cPLA2 and triggers necrotic cell death. This work demonstrates that in contrast to reactive UPR activators that kill cells through $\mathrm{CHOP}$ mediated apoptosis, BHPI, a small-molecule activator of the anticipatory UPR, kills cells through necrosis. Importantly, ATP depletion is the critical cause of necrotic cell death after strong and sustained activation of the anticipatory UPR. Thus, we show that different modes of UPR activation trigger different death pathways.

\section{Materials and methods}

\section{Cell culture and reagents}

T47D, MCF7, ECC-1, MDA MB-231, HeLa, ES2, HEK 293T, and MCF10A cells were from ATCC. BT-474 cells

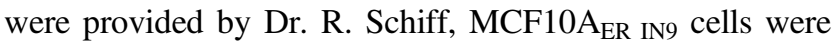

provided by Dr. B.H. Park, and TamR cells were provided by Dr. D. McDonnell. T47D-ER $\alpha$ Y537S (TYS) and T47D$\mathrm{ER} \alpha \mathrm{D} 538 \mathrm{G}$ (TDG) were made as we recently described [16]. Cells were grown in the following conditions: T47D (MEM, 10\% FBS), ER $\alpha$ Y537S and ER $\alpha$ D538G (MEM, 10\% charcoal:dextran-treated (CD)-FBS), MCF-7 (MEM, 5\% FBS), ECC-1 (RPMI, 5\% FBS), MDA MB-231 (MEM, 5\% FBS), HeLa (RPMI1640, 10\% FBS), ES2 (McCoy's 5a, 10\% FBS), HEK 293T (DMEM, 10\% FBS), MCF10A and MCF10A BT-474 (RPMI1640, 10\% FBS), and TamR (DMEM/F12 + NEAA + $100 \mathrm{nM}$ z-OHT, 8\% FBS). Reagents used were: trans-ISRIB, SKF 96365, and BAPTA-AM (Cayman Chemical, MI), fulvestrant/ICI 182,780 (Tocris Bioscience, $\mathrm{MN}$ ), bortezomib, 7-Cl-O-Nec-1, and GSK872 (EMD Millipore, MA), niflumic acid, quinacrine dihydrochloride, and Z-VAD-FMK (Santa Cruz Biotechnology, TX), ${ }^{3} \mathrm{H}$-arachidonic acid and ${ }^{35} \mathrm{~S}$-methionine (Perkin Elmer, MA), all other reagents were from Sigma Aldrich (MO).

\section{Cell proliferation}

Cells were plated at the indicated density into 96-well plates. The next day, the medium was changed to one containing the indicated treatment. The medium was changed again after 2 days and proliferation assayed after a total of 4 days. Cell number was measured with Alamar Blue (ThermoFisher, MA) and compared to a standard curve of cell number vs. fluorescence.

\section{Western blotting}

Western blotting was carried out as previously described [7, 59]. The following primary antibodies were used: PARP (Cell Signaling Technology (CST) \# 9532), Bcl2 (CST \# 4223), LC3A/B (CST \# 4108), Beclin-1 (CST \# 3738), CHOP (CST \# 2895), p-p70S6K (T389) (CST \# 9234), ER $\alpha$ (CST \# 8644), HMGB1 (Novus Biologicals, 2F6), PLC $\gamma$ (CST \# 5690), and $\beta$-actin (Sigma, A1978). Antibodies were probed with HRP-conjugated secondary antibodies (ThermoFisher) and imaged with the ECL2 detection kit (Fisher Scientific, MA) using a PhosphorImager.

\section{Trypan blue exclusion and cell swelling}

Cell viability or cell diameter after treatment with BHPI or other compounds were measured using a Countess II cell counter (ThermoFisher). 300,000 cells/well were plated in six-well plates. The next day, vehicle or treatment was added for the indicated time. Cells were then harvested and concentrated to 2-5 million cells $/ \mathrm{ml}$ before addition of trypan blue immediately before counting for cell viability or diameter. 


\section{Lentiviral production}

Constructs for packaging vectors pCI-VSVG (\# 1733) and psPAX2 (\# 12260), pHIV-Luciferase (\# 21375), and pCDH-Bcl2 (\# 46971) were from Addgene (MA). Lentiviral packaging vectors were co-transfected with either luciferase or Bcl2 into HEK 293 T cells with Lipofectamine 3000 (Invitrogen, CA). The next day, medium was changed. Virus was harvested $24 \mathrm{~h}$ later and used to infect TYS cells for $48 \mathrm{~h}$ before analysis of trypan blue uptake or western blotting.

\section{Flow cytometry}

300,000 cells/well were plated in 6-well plates. The next day, vehicle or treatment was added for the indicated time. Cells were then harvested, washed with PBS, and stained with the Dead Cell Apoptosis Kit (ThermoFisher). After staining, cells were measured on a BD LSR II (BD Biosceinces, NJ) and data was analyzed using FCS Express (DeNovo, CA).

\section{Transmission electron microscopy}

The cell pellet was fixed in a Karnovsky's Fixative in phosphate-buffered $2 \%$ glutaraldeyde and $2.5 \%$ paraformaldehyde. Microwave fixation was used with this primary fixative and the tissue was then washed in Sorenson's phosphate buffer without additives. Microwave fixation was also used with the secondary $2 \%$ osmium tetroxide fixative, followed by the addition of 3\% potassium ferricyanide for $30 \mathrm{~min}$. After washing with water, saturated uranyl acetate was added for enbloc staining. The tissue was dehydrated with a series containing increasing concentrations of ethanol. Acetonitrile was used as the transition fluid between ethanol and the epoxy. Infiltration series was done with an epoxy mixture using the epon substitute Lx112. The resulting blocks were polymerized at $9{ }^{\circ} \mathrm{C}$ overnight, trimmed and ultrathin sectioned with diamond knives. Sections were stained with uranyl acetate and lead citrate and examined or photographed with a Hitachi H600 Transmission Electron Microscope at $75 \mathrm{KV}$.

\section{Lactate dehydrogenase (LDH) release}

LDH release into the medium was measured according to the CytoTox-ONE Homogeneous Membrane Integrity Assay protocol (Promega, WI).

\section{siRNA knockdown of ERa and PLCY}

Knockdown of ER $\alpha$ or PLC $\gamma$ was performed using DharmaFECT1 transfection reagent and $100 \mathrm{nM}$ ON-
TARGETplus non-targeting pool or SMARTpool for ER $\alpha$ (ESR1) or PLC $\gamma$ (PLCG1) (Dharmacon, CO). T47D or TYS cells were treated with non-coding or coding siRNA for $16 \mathrm{~h}$ and the medium was replaced thereafter. To further reduce the levels of ER $\alpha, 24 \mathrm{~h}$ after changing the medium, $1 \mu \mathrm{M}$ of ICI was added to the samples that received ER $\alpha$ siRNA and vehicle was added to the untreated and noncoding samples. Cell swelling was assayed after an additional $24 \mathrm{~h}$. Trypan blue uptake in TYS cells was measured $48 \mathrm{~h}$ following transfection.

\section{Protein synthesis}

Rates of protein synthesis were evaluated by measuring ${ }^{35} \mathrm{~S}$-methionine incorporation into newly synthesized protein as described previously [14]. Briefly, cells were incubated with treatment for the indicated time and $3 \mu \mathrm{Ci}$ ${ }^{35} \mathrm{~S}$-methionine was added for the last $30 \mathrm{~min}$ of treatment. Cells were washed with PBS and lysed in RIPA buffer. Lysates were spun and supernatants were pipetted onto Whatman 540 filter-paper discs and subsequently washed $3 \times$ each with $10 \%$ TCA, then 5\% TCA, and air dried. Protein was solubilized and counts were measured to determine percent protein synthesis inhibition.

\section{${ }^{3} \mathrm{H}$-Arachidonic acid release from cell membranes}

Phospholipase cleavage of arachidonic acid (AA) from membranes was determined by measuring release of ${ }^{3} \mathrm{H}-\mathrm{AA}$ into medium. To allow overnight incorporation into membranes, 100,000 cells/well were plated in a 24-well plate and incubated overnight in medium containing $0.1 \%$ fatty acid-free BSA and ${ }^{3} \mathrm{H}-\mathrm{AA}$ to a final concentration of $0.1 \mu \mathrm{Ci} / \mathrm{ml}$. The next day, the medium was removed, and cells were washed $4 \times$ with incubation medium $(25 \mathrm{mM}$ HEPES pH 7.2, $150 \mathrm{mM} \mathrm{NaCl}, 5 \mathrm{mM} \mathrm{KCl}, 5.5 \mathrm{mM}$ dextrose, $0.8 \mathrm{mM} \mathrm{MgSO}_{4}, 1 \mathrm{mM} \mathrm{CaCl} 2,0.1 \%$ BSA). Incubation medium containing the treatment was added and cells were incubated at $37{ }^{\circ} \mathrm{C}$ for $45 \mathrm{~min}$. Medium was collected, and cells were lysed in $0.1 \mathrm{M} \mathrm{NaOH} .{ }^{3} \mathrm{H}$ counts for the medium and cell lysates were determined and AA release was normalized to total incorporated label.

\section{BHPI-stimulated prostaglandin release}

Cells were plated to $70 \%$ confluency; the next day, the medium was changed to MEM $+0.1 \%$ BSA with treatment. Twenty-four hours later, the medium was collected, spun down, and the supernatant was collected and evaporated before resuspension and analysis following the Prostaglandin Screening Kit protocol (Cayman Chemical). 


\section{ATP measurement}

ATP depletion was performed as previously described [14] and ATP levels were measured according to the ATPlite Luminescence Assay Kit protocol (Perkin Elmer).

Acknowledgements Electron microscopy was performed in the Frederick Seitz Materials Research Laboratory Central Research Facilities and flow cytometry was done at the Roy J. Carver Biotechnology Center, University of Illinois. We thank Michael Lambrecht for synthesizing BHPI. This research was supported by grants DOD BCRP W81XWH-13, NIH RO1 DK071909, and the E. Howe Scholar Award (DJS), and by an NSF Graduate Research Fellowship under DGE1144245 (ML).

\section{Compliance with ethical standards}

Conflict of interest The authors declare that they have no conflict of interest.

\section{References}

1. Walter P, Ron D. The unfolded protein response: from stress pathway to homeostatic regulation. Science. 2011;334:1081-6.

2. Ma Y, Hendershot LM. The role of the unfolded protein response in tumour development: friend or foe? Nat Rev Cancer. 2004;4:966-77.

3. Wang M, Kaufman RJ. The impact of the endoplasmic reticulum protein-folding environment on cancer development. Nat Rev Cancer. 2014;14:581-97.

4. Lee AS. GRP78 induction in cancer: therapeutic and prognostic implications. Cancer Res. 2007;67:3496-9.

5. Urra H, Dufey E, Avril T, Chevet E, Hetz C. Endoplasmic reticulum stress and the hallmarks of cancer. Trends Cancer. 2016;2:252-62.

6. Shapiro DJ, Livezey M, Yu L, Zheng X, Andruska N. Anticipatory UPR activation: a protective pathway and target in cancer. Trends Endocrinol Metab. 2016;27:731-41.

7. Andruska N, Zheng X, Yang X, Helferich WG, Shapiro DJ. Anticipatory estrogen activation of the unfolded protein response is linked to cell proliferation and poor survival in estrogen receptor $\alpha$-positive breast cancer. Oncogene. 2015;34:3760-9.

8. Yu L, Andruska N, Zheng X, Shapiro DJ. Anticipatory activation of the unfolded protein response by epidermal growth factor is required for immediate early gene expression and cell proliferation. Mol Cell Endocrinol. 2016;422:31-41.

9. Karali E, Bellou S, Stellas D, Klinakis A, Murphy C, Fotsis T. VEGF signals through ATF6 and PERK to promote endothelial cell survival and angiogenesis in the absence of ER stress. Mol Cell. 2014;54:559-72.

10. Onuki R, Bando Y, Suyama E, Katayama T, Kawasaki H, Baba T, et al. An RNA-dependent protein kinase is involved in tunicamycin-induced apoptosis and Alzheimer's disease. EMBO J. 2004;23:959-68.

11. Yamaguchi H, Bhalla K, Wang H-G. Bax plays a pivotal role in thapsigargin-induced apoptosis of human colon cancer HCT116 cells by controlling Smac/Diablo and $\mathrm{Omi} / \mathrm{HtrA} 2$ release from mitochondria. Cancer Res. 2003;63:1483-9.

12. Nawrocki ST, Carew JS, Pino MS, Highshaw RA, Dunner K, Huang $\mathrm{P}$, et al. Bortezomib sensitizes pancreatic cancer cells to endoplasmic reticulum stress-mediated apoptosis. Cancer Res. 2005;65:11658-66.
13. Ron D, Walter P. Signal integration in the endoplasmic reticulum unfolded protein response. Nat Rev Mol Cell Biol. 2007;8: 519-29.

14. Andruska ND, Zheng X, Yang X, Mao C, Cherian MM, Mahapatra L, et al. Estrogen receptor $\alpha$ inhibitor activates the unfolded protein response, blocks protein synthesis, and induces tumor regression. Proc Natl Acad Sci USA. 2015;112: 4737-42.

15. Zheng X, Andruska N, Lambrecht MJ, He S, Parissenti A, Hergenrother PJ, et al. Targeting multidrug-resistant ovarian cancer through estrogen receptor $\alpha$ dependent ATP depletion caused by hyperactivation of the unfolded protein response. Oncotarget. 2016;9:14741-53.

16. Mao C, Livezey M, Kim JE, Shapiro DJ. Antiestrogen resistant cell lines expressing estrogen receptor $\alpha$ mutations upregulate the unfolded protein response and are killed by BHPI. Sci Rep. 2018;6:34753.

17. Sykes EK, Mactier S, Christopherson RI. Melanoma and the unfolded protein response. Cancers. 2016;8. https://doi.org/10. 3390/cancers 8030030

18. Hensel F, Eckstein M, Rosenwald A, Brändlein S. Early development of PAT-SM6 for the treatment of melanoma. Melanoma Res. 2013;23:264-75.

19. Fasano E, Serini S, Piccioni E, Toesca A, Monego G, Cittadini AR, et al. DHA induces apoptosis by altering the expression and cellular location of GRP78 in colon cancer cell lines. Biochim Biophys Acta. 2012;1822:1762-72.

20. Wright TM, Wardell SE, Jasper JS, Stice JP, Safi R, Nelson ER, et al. Delineation of a FOXA1/ER $\alpha / A G R 2$ regulatory loop that is dysregulated in endocrine therapy-resistant breast cancer. Mol Cancer Res MCR. 2014;12:1829-39.

21. Sano R, Reed JC. ER stress-induced cell death mechanisms. Biochim Biophys Acta. 2013;1833:3460-70.

22. Devarajan E, Sahin AA, Chen JS, Krishnamurthy RR, Aggarwal N, Brun A-M, et al. Down-regulation of caspase 3 in breast cancer: a possible mechanism for chemoresistance. Oncogene. 2002;21: 8843-51.

23. Mooney LM, Al-Sakkaf KA, Brown BL, Dobson PRM. Apoptotic mechanisms in T47D and MCF-7 human breast cancer cells. Br J Cancer. 2002;87:909-17.

24. Zhang Y, Zhang B. TRAIL resistance of breast cancer cells is associated with constitutive endocytosis of death receptors 4 and 5. Mol Cancer Res MCR. 2008;6:1861-71.

25. Kim I, Xu W, Reed JC. Cell death and endoplasmic reticulum stress: disease relevance and therapeutic opportunities. Nat Rev Drug Discov. 2008;7:1013-30.

26. Nishitoh H. CHOP is a multifunctional transcription factor in the ER stress response. J Biochem (Tokyo). 2012;151:217-9.

27. Oyadomari S, Mori M. Roles of CHOP/GADD153 in endoplasmic reticulum stress. Cell Death Differ. 2004;11:381-9.

28. Kaur J, Debnath J. Autophagy at the crossroads of catabolism and anabolism. Nat Rev Mol Cell Biol. 2015;16:461-72.

29. Ogata M, Hino S, Saito A, Morikawa K, Kondo S, Kanemoto S, et al. Autophagy is activated for cell survival after endoplasmic reticulum stress. Mol Cell Biol. 2006;26:9220-31.

30. Deegan S, Saveljeva S, Logue SE, Pakos-Zebrucka K, Gupta S, Vandenabeele P, et al. Deficiency in the mitochondrial apoptotic pathway reveals the toxic potential of autophagy under ER stress conditions. Autophagy. 2014;10:1921-36.

31. Kang R, Zeh HJ, Lotze MT, Tang D. The Beclin 1 network regulates autophagy and apoptosis. Cell Death Differ. 2011;18: 571-80.

32. Mizushima N, Komatsu M. Autophagy: renovation of cells and tissues. Cell. 2011;147:728-41.

33. Jewell JL, Russell RC, Guan K-L. Amino acid signalling upstream of mTOR. Nat Rev Mol Cell Biol. 2013;14:133-9. 
34. Majno G, Joris I, Apoptosis, oncosis, and necrosis. An overview of cell death. Am J Pathol. 1995;146:3-15.

35. Mouchlis VD, Dennis EA. Membrane and inhibitor interactions of intracellular phospholipases A2. Adv Biol Regul. 2016;61:17-24.

36. Burke JE, Dennis EA. Phospholipase A2 structure/function, mechanism, and signaling. J Lipid Res. 2009;50:S237-42.

37. Enyedi B, Jelcic M, Niethammer P. The cell nucleus serves as a mechanotransducer of tissue damage-induced inflammation. Cell. 2016;165:1160-70.

38. Lang F, Busch GL, Ritter M, Völkl H, Waldegger S, Gulbins E, et al. Functional significance of cell volume regulatory mechanisms. Physiol Rev. 1998;78:247-306.

39. Staub F, Winkler A, Peters J, Kempski O, Kachel V, Baethmann A. Swelling, acidosis, and irreversible damage of glial cells from exposure to arachidonic acid in vitro. J Cereb Blood Flow Metab J Int Soc Cereb Blood Flow Metab. 1994;14:1030-9.

40. Miller SB. Prostaglandins in health and disease: an overview. Semin Arthritis Rheum. 2006;36:37-49.

41. Gilroy DW, Newson J, Sawmynaden P, Willoughby DA, Croxtall JD. A novel role for phospholipase A2 isoforms in the checkpoint control of acute inflammation. FASEB J Publ Fed Am Soc Exp Biol. 2004;18:489-98.

42. Leist M, Single B, Castoldi AF, Kühnle S, Nicotera P. Intracellular adenosine triphosphate (ATP) concentration: a switch in the decision between apoptosis and necrosis. $\mathbf{J}$ Exp Med. 1997;185:1481-6.

43. Criddle DN, Gerasimenko JV, Baumgartner HK, Jaffar M, Voronina S, Sutton R, et al. Calcium signalling and pancreatic cell death: apoptosis or necrosis? Cell Death Differ. 2007;14:1285-94.

44. Zong W-X, Ditsworth D, Bauer DE, Wang Z-Q, Thompson CB. Alkylating DNA damage stimulates a regulated form of necrotic cell death. Genes Dev. 2004;18:1272-82.

45. Golstein P, Kroemer G. Cell death by necrosis: towards a molecular definition. Trends Biochem Sci. 2007;32:37-43.

46. Krysko DV, Vanden Berghe T, Parthoens E, D'Herde K, Vandenabeele P. Methods for distinguishing apoptotic from necrotic cells and measuring their clearance. Methods Enzymol. 2008;442:307-41.

47. McKeague AL, Wilson DJ, Nelson J. Staurosporine-induced apoptosis and hydrogen peroxide-induced necrosis in two human breast cell lines. Br J Cancer. 2003;88:125-31.
48. Cai Z, Liu Z-G. Execution of RIPK3-regulated necrosis. Mol Cell Oncol. 2014;1. https://doi.org/10.4161/23723548.2014.960759

49. Vandenabeele $\mathrm{P}$, Grootjans S, Callewaert N, Takahashi N. Necrostatin-1 blocks both RIPK1 and IDO: consequences for the study of cell death in experimental disease models. Cell Death Differ. 2013;20:185-7.

50. Mandal P, Berger SB, Pillay S, Moriwaki K, Huang C, Guo H, et al. RIP3 induces apoptosis independent of pronecrotic kinase activity. Mol Cell. 2014;56:481-95.

51. Sidrauski C, Tsai JC, Kampmann M, Hearn BR, Vedantham P, Jaishankar $\mathrm{P}$, et al. Pharmacological dimerization and activation of the exchange factor eIF2B antagonizes the integrated stress response. eLife. 2015;4:e07314.

52. Hernandez CC, Zaika O, Tolstykh GP, Shapiro MS. Regulation of neural KCNQ channels: signalling pathways, structural motifs and functional implications. J Physiol. 2008;586:1811-21.

53. Castro J, Bittner CX, Humeres A, Montecinos VP, Vera JC, Barros LF. A cytosolic source of calcium unveiled by hydrogen peroxide with relevance for epithelial cell death. Cell Death Differ. 2004;11:468-78.

54. Bruce JIE. Metabolic regulation of the PMCA: role in cell death and survival. Cell Calcium. 2018;69:28-36.

55. Maiuri MC, Zalckvar E, Kimchi A, Kroemer G. Self-eating and self-killing: crosstalk between autophagy and apoptosis. Nat Rev Mol Cell Biol. 2007;8:741-52.

56. Vanlangenakker N, Vanden Berghe T, Krysko DV, Festjens N, Vandenabeele P. Molecular mechanisms and pathophysiology of necrotic cell death. Curr Mol Med. 2008;8:207-20.

57. Workenhe ST, Mossman KL. Oncolytic virotherapy and immunogenic cancer cell death: sharpening the sword for improved cancer treatment strategies. Mol Ther J Am Soc Gene Ther. 2014;22:251-6.

58. Vandenberk L, Belmans J, Van Woensel M, Riva M, Van Gool SW. Exploiting the immunogenic potential of cancer cells for improved dendritic cell vaccines. Front Immunol. 2015;6:663.

59. Andruska N, Mao C, Cherian M, Zhang C, Shapiro DJ. Evaluation of a luciferase-based reporter assay as a screen for inhibitors of estrogen-ER $\alpha$-induced proliferation of breast cancer cells. J Biomol Screen. 2012;17:921-32. 